\title{
ENSAIO SOBRE APLICAÇÕES DIDÁTICAS DA TEORIA DE REPRESENTAÇÃO SOCIAL
}

\section{DIDACTICAL APPLICATIONS OF THE SOCIAL REPRESENTATION THEORY}

\author{
Mary RANGEL*
}

Resumo: Este estudo tem o propósito de sugerir aos professores que considerem a possibilidade de aplicação didática de categorias da representação social, com particular atenção à sua estrutura, constituída de um núcleo central e elementos periféricos. No estilo de um ensaio, o texto desenvolve uma argumentação apoiada em premissas teóricas que sustentam a seqüência das análises. O ensaio admite um encadeamento de idéias de modo menos rígido e mais flexível, sem pretender afirmações conclusivas, ou comprovação e generalização de dados. Enfatiza-se, na aplicação didática da teoria de representação social, a atenção a conceitos, observando-se o núcleo de significados em torno do qual se organizam as noções complementares. Desse modo, sugere-se que no processo de ensino-aprendizagem o professor fique atento à estrutura de cada conceito, de acordo com referências da estrutura das representações. Com essa proposta, o presente estudo insere-se também no movimento em favor da consolidação do vínculo entre ensino e pesquisa, observando que os princípios de uma teoria poderão também, conforme o encaminhamento de sua formulação, ser considerados como princípios didáticos.

Palavras-chave: Ensino. Pesquisa. Representação Social. Didática.

* Professora da Universidade Federal Fluminense e da Universidade do Estado do Rio de Janeiro; Doutorado em Educação, com Pós-Doutorado na área de Psicologia Social. E-mail: mrangel@ abel.org.br 


\begin{abstract}
This study suggests that teachers consider the possibility of the didactical application of the social representation theory with particular attention to its structure which is constituted of a core nucleus and peripherical elements. In the style of an essay, the text develops an argument based on the theoretical premises that support the sequence of analysis. The essay admits the development of ideas in a less rigid and more flexible way without intending to provide conclusive affirmations or the confirmation and generalization of data. It is emphasized the attention to concepts in the didactical application of the social representation theory, observing the nucleus of meanings around which the complementary notions are organized. This way it is suggested that in the process of teaching-learning teachers pay attention to the structure of each concept according to the references of the structure of the representations. With this proposal, the present study is part of the movement which favors the consolidation of the links between teaching and research observing that the principles of a theory can be, depending on its formulation, considered as didactical principles.
\end{abstract}

Keywords: Teaching. Research. Social Representation. Didactics.

\title{
INTRODUÇÃO
}

Este artigo desenvolve, em forma de um ensaio, considerações sobre a possibilidade de aplicação didática da teoria de representação social.

Os objetivos que orientam as análises formulam-se em duas perspectivas, que se associam e se complementam. A primeira perspectiva é a de enfatizar o sentido das representações como forma de conhecimento prático, reunindo argumentos no interesse de demonstrar que o modo como as representações são "construídas e adquiridas" (MOSCOVICI, 2001, p. 62) também pode ser considerado no modo como se constroem e adquirem os conceitos no processo de ensino- 
aprendizagem. A segunda perspectiva é a de sugerir aos professores que considerem a possibilidade de aplicação didática das categorias de representação social e que dêem particular atenção à estrutura dessas categorias, assim como aos princípios e noções que fundamentam e explicam o seu núcleo central e os elementos periféricos.

Com esses objetivos, este trabalho representa também uma forma de se participar do movimento em favor da consolidação do vínculo entre ensino e pesquisa (BRASIL, 1999; FAZENDA, 1998; LEAHEY e HARRIS, 2O00; OCHOA, 2OOO; PERRENOUD et al., Orgs., 2001; ROSA e SOUZA, Orgs., 2002), observando-se que os princípios de uma teoria poderão também, conforme o encaminhamento de sua formulação, ser considerados como princípios didáticos.

Assim, reúnem-se premissas teóricas e argumentos por meio dos quais se procura alcançar os objetivos pretendidos. A argumentação foi construída de acordo com esses objetivos e com o estilo e proposta do presente estudo, adotando-se o ensaio como opção metodológica.

\section{O ENSAIO COMO OPÇÃO METODOLÓGICA}

Embora se constate, atualmente, a preocupação de pesquisadores quanto a um maior rigor metodológico, encontram-se também endossos teóricos - como nos trabalhos de Lefebvre (1983) e Moscovici (1988) - a alternativas mais flexíveis de produção do conhecimento, desde que, naturalmente, adequadas ao seu propósito e proposta.

Vale, também, notar a posição de Moscovici (2001, p. 46), favorável à convergência entre as áreas de conhecimento, desejando que “...essa convergência resulte em comunicação e colaboração mais estreitas, uma fecundação recíproca dos trabalhos". Essa posição favorece a recorrência ao ensaio não só como gênero literário, mas também como gênero de pesquisa, ou seja, como estilo de produção de conhecimento que traz da literatura subsídios a diversas outras áreas.

Enfoques mais amplos e flexíveis de metodologia de pesquisa, como os de Cardoso e Malerba (Orgs., 2000) e Moreira e Oliveira (Orgs., 1998), também corroboram o princípio de contribuições multidisciplinares de construção do saber, ampliando suas possibilidades e suas alternativas. Considerações desse teor sustentam a recorrência ao gênero ensaístico, de crescente aplicação em áreas como a História, 
a Antropologia e a Filosofia (BURKE, 1987).

Para a caracterização metodológica do ensaio, escolheram-se aportes de Arrigucci Junior (1973), Bauer, Gaskell (2002), Burke (1987), Pinto (1998), iniciando-se pela definição semântica de Ferreira (1986).

Do ponto de vista semântico, pode-se compreender o ensaio como uma "dissertação mais curta e menos metódica do que um tratado formal e acabado" (FERREIRA, 1986, p.77). Esse desenho menos rígido e mais flexível de encaminhamento de análises e proposições que suscitam e sugerem continuidade, seja para confirmações, seja para questionamentos, encontra também respaldo em Moscovici (1978, p. 35), quando se refere ao seu próprio estudo como "provisório e aberto".

Burke (1987) reafirma a importância do ensaio e seus expressivos subsídios à produção, teórica e logicamente sustentada, de conhecimento. Como exemplos de ensaístas de reconhecida consideração científica, indica Carlo Ginzgurg, na História; Clifford Geertz, na Antropologia; e Richard Rorty, na Filosofia. Com essa exemplificação, Burke (1987) confirma, também, o princípio de que o estilo ensaístico evita afirmações e definições conclusivas, assim como não pretende e não propõe generalizações.

Com o mesmo entendimento, Pinto (1998, p. 38) destaca o antidogmatismo do ensaio, que se caracteriza por análises fundamentadas e articulações de raciocínios, seguindo uma "estratégia geral de enunciação", através da qual se formulam e propõem idéias e argumentos.

Reconhecendo essas mesmas características, Arrigucci Junior (1973, p. 16) observa, no ensaio, a tentativa de apreensão do objeto e o encaminhamento de raciocínios que estabelecem "liames seguros entre as partes e o todo, travadas relações entre os elementos estruturais da argumentação". Argumentar e persuadir são estilos e propostas do ensaio.

Para compreender melhor a estratégia de persuasão, recorrese também a Bauer e Gaskell (2002, p. 28), quando mencionam a retórica e a "arte de persuadir", assinalando que "...a pesquisa social científica é uma forma de retórica, com meios e normas específicas de engajamento". $\mathrm{Na}$ "arte de persuadir", observam-se "o logos, o pathos e o ethos". O "logos" refere-se à lógica e ao tipo de argumentos; o "pathos" refere-se ao apelo para que esses argumentos sejam 
reconhecidos, aceitos; o "ethos" refere-se aos fatores e fundamentos que conferem legitimidade e credibilidade à argumentação.

Com esse entendimento, observa-se também que, no encaminhamento da pesquisa e na comunicação de seus resultados, o "ideal científico" das comparações, sem "pathos" ou "ethos", é uma ilusão.

É possível, então, "considerar a metodologia de pesquisa social como meio retórico, através do qual as ciências sociais podem reforçar sua forma específica de persuasão" (BAUER; GASKELL, 2002, p. 28).

Todas essas considerações teóricas permitem reafirmar o ensaio como uma dissertação pouco extensa, na qual o autor/pesquisador constrói o seu objeto através de um encadeamento de raciocínios (lógicos, fundamentados) que estruturam sua argumentação.

Ainda, de acordo com o estilo ensaístico, a dissertação não se encerra nos limites de seus termos e proposições. Ao contrário, a inconclusão de um ensaio tem o especial valor de suscitar e sugerir o seu prosseguimento. Assim acontece com este ensaio, cujo objeto, a possibilidade de aplicação didática da teoria de representação social, constitui-se numa sugestão ao debate dos pesquisadores, esperando-se persuadi-los a considerá-la em suas investigações, seja para encontrar novas perspectivas, seja para confirmar ou refutar as que este ensaio lhes oferece, através da construção de seus argumentos.

\section{ANÁLISE DE POSSIBILIDADES DE APLICAÇÃO DIDÁTICA DA TEORIA DE REPRESENTAÇÃO SOCIAL}

Os argumentos à aplicação didática da estrutura da representação social (RS) iniciam-se por compreender, em Moscovici (1978, p. 62), que a representação, como forma de conhecimento prático, elaborado no cotidiano da vida social, promove a "popularização" e "familiarização" do saber, trazendo-o para o "universo interior" dos sujeitos.

Um dos elos mais expressivos entre a incorporação do conhecimento no processo de formação das representações e a incorporação do conhecimento no processo de ensino-aprendizagem é observado por Moscovici, quando aponta, na representação, o movimento pelo qual o indivíduo procura entender, trazer para o seu "universo interior", absorver o que está distante de sua compreensão e experiência. Esse 
movimento é, sem dúvida, uma referência importante ao processo de ensino-aprendizagem.

Entre os muitos estímulos de Moscovici (2001, p. 63) à atenção dos pesquisadores quanto às possibilidades e contribuições do estudo da representação social, encontra-se a seguinte observação: "Cada vez que um saber é gerado e comunicado, torna-se parte da vida coletiva, isso nos diz respeito e, em particular, quando esse saber, enquanto tal, serve para a solução de algum problema social...".

Encontra-se, portanto, nesse enfoque, mais um argumento a este ensaio, no qual se reconhece, na teoria de representação social, a possibilidade de contribuir com o ensino-aprendizagem, cujas dificuldades têm implicações em problemas sociais significativos, gerados pelos fatores persistentes do fracasso e da exclusão escolar e social.

Na mesma linha de raciocínio, Jodelet (2001, p. 17) reafirma a importância das representações sociais, observando que são "criadas" pelos sujeitos para conhecer o mundo à sua volta e "resolver problemas". O saber constituído pelas representações ajuda a compreender, reconstituir, interpretar os objetos do cotidiano. Ainda, referindo-se à relação sujeito-objeto e à representação mental, a autora exemplifica a representação pictórica, a política e a teatral, assinalando a condição de, pela reconstituição simbólica, superar a ausência e a distância do objeto e fazê-lo presente.

Quanto à representação teatral, é interessante também considerar Goffman (2002). Utilizando como parâmetro a representação e a linguagem do teatro, o autor focaliza a influência das representações nas relações e atividades dos indivíduos no contexto de seus grupos sociais. Em síntese, os homens, os objetos, tanto no teatro como na vida cotidiana, tornam-se conhecidos, entre outros fatores, através da representação. Acentua-se, desse modo, o potencial da representação como forma de conhecimento.

A apreensão dos objetos, o conjunto de informações que sobre eles se formam no dia-a-dia, o campo que essas informações configuram, com núcleos fortes de significados, a imagem que, concreta e mentalmente, reproduz o objeto são realçados por Santiago (2000), que enfatiza os processos sociocognitivos e sócio-afetivos da representação, intervenientes no grau de conhecimento dos objetos e na valorização que os sujeitos lhes atribuem. Especialmente o núcleo de significados (núcleo central) da representação e a imagem mental que ela sugere e transmite favorecem a superação da dicotomia entre o 
universo interior e o universo exterior dos sujeitos.

Na superação dessa dicotomia, Abric (1998, p. 27), em sua "abordagem estrutural", assinala como "característica específica da representação social" a de "ser organizada em torno de um núcleo central, constituindo-se em um ou mais elementos, que dão significado à representação". Em torno desse núcleo, organizam-se os elementos periféricos, que são os componentes estruturais "mais acessíveis e mais vivos".

O núcleo tem função geradora, no sentido de criar ou transformar significados, e organizadora, no sentido de estabelecer elos entre esses significados. Os elementos periféricos têm três funções principais: a de constituir a interface entre o núcleo central e a situação concreta na qual a representação se forma, a de adaptar a representação às evoluções e alterações de contexto, a de preservar e manter a representação (ABRIC, 1998).

Flament (2001) observa, também, que os esquemas periféricos confirmam, protegem, estabelecem mediações entre o núcleo central e a realidade, absorvendo possíveis diferenças e contribuindo para a situação "relativamente" estável da representação.

Ao estabelecer um profícuo diálogo com Flament e outros autores expressivos, como Abric e Farr, Celso Sá (1996) focaliza a teoria do núcleo central, destacando-o na estrutura da representação e observando a sua complementação nos esquemas periféricos. Assim, o núcleo é enfatizado como o centro da organização das representações, no qual se condensam seus significados.

Embora reconheça posições teóricas que admitem a representação sem o núcleo central, Sá (1996), com base em Flament, considera a presença do núcleo como lugar no qual se consolidam as articulações da representação com o objeto da realidade a que se refere. Prosseguindo nessa perspectiva, quando trata da construção do objeto de representações, Sá (1998), lembrando Jodelet, reafirma a representação como forma de saber que liga o sujeito ao objeto.

Nessa mesma perspectiva, enfatizando a representação como atividade simbólica de (re)conhecimento dos objetos e destacando o seu "caráter tanto referencial como construtivista", Jovchelovitch (2001) reafirma que o mundo, mediado pela representação social, é o lugar do conhecimento na relação entre o sujeito e o objeto.

Desse modo, pontuando os significados que se centram e concentram no núcleo central, assim como os elementos ou esquemas 
periféricos que complementam e reafirmam o núcleo, revê-se novamente Abric, em Sá (1996, p. 54), quando caracteriza a noção de representação como o "produto e o processo de uma atividade mental pela qual um indivíduo ou um grupo reconstituem o real com que se confrontam e lhe atribuem uma significação específica".

Ao discutir questões epistemológicas do conhecimento cotidiano, escolar e científico, Arnay (1998, p. 38) colabora com a argumentação, observando que tanto a maneira como os indivíduos adquirem o conhecimento de senso comum, como a quantidade expressiva de informações, valores, crenças, expectativas que esse tipo de conhecimento incorpora e acumula, deveriam ser mais consideradas nos processos escolares.

Chega-se, então, com essas premissas teóricas, a compor uma base de argumentos no sentido da transposição didática, ou seja, da transferência, da utilização didática (LEAHEY; HARRIS, 2000; OCHOA, 2OOO; ROSA; SOUZA, Orgs., 2002) da representação social, com atenção à sua estrutura.

Revê-se, mais uma vez, a representação social como forma de conhecimento dos objetos pelos sujeitos, tornando-os "familiares" (menos estranhos), trazendo-os do "exterior" para o "universo interior", "ancorando-os", sedimentando-os.

Se os objetos do conhecimento teórico são, em princípio, estranhos aos sujeitos; se a representação social é uma forma de conhecimento pela qual os objetos tornam-se "familiares" e são incorporados, assimilados, é possível observar, na constituição das representações, o seu potencial didático.

Pode-se, portanto, reconhecer, no modo como as representações são formadas, um processo didático de assimilação e compreensão do conhecimento. Acredita-se que esse processo possa ser sistematizado, previsto, empregado de forma mais organizada como recurso metodológico de ensino-aprendizagem.

Levando em conta o produto e a estrutura das representações, observa-se a importância de conceitos e, neles, de núcleos fortes de significados que os concretizam, e de elementos ou esquemas periféricos que, segundo Moliner (apud SÁ, 1996), apresentam características do objeto da representação. Assim, mais ousadamente, porém de modo sustentado pela argumentação, pode-se pensar em procedimentos de ensino-aprendizagem de conceitos, baseados em princípios da representação social. 
Este ensaio oferece, então, ao professor, sugestões de procedimentos, sem pretender que sejam "novos" na literatura, na concepção ou na justificativa de sua aplicação didática, mas apenas "novos" nas referências teóricas da representação social e na proposta de sistematização do uso didático dessas referências. Essa sistematização é a que se apresenta, em seguida, a partir da atenção a conceitos, a processos de conversação e interação (no curso dos quais as representações são formadas e incorporadas ao pensamento e à linguagem social) e ao núcleo central de significados e seus elementos periféricos, procurando reconhecê-los nos fatos, situações, experiências da vida cotidiana.

Assim, para a possibilidade de aplicação didática da teoria de representação social, ensaia-se um fluxo (um encaminhamento integrado, articulado, contextualizado) de procedimentos, a serem adotados no ensino-aprendizagem de conceitos. Nesse fluxo, caberia ao professor:

- Introduzir a aprendizagem dos objetos do conhecimento pelos seus conceitos.

- Observar a estrutura de cada conceito, de acordo com referências da estrutura da representação social, procurando, então, identificar um núcleo, onde se consubstanciam, articulam e aglutinam os significados mais relevantes, mais representativos do objeto do conhecimento a que o conceito se refere, e as noções no seu entorno, que o complementam, reforçam, exemplificam.

- Analisar, a partir da estrutura do conceito, seu núcleo de significados e as noções complementares ao núcleo, observando suas possíveis aplicações práticas na vida, no cotidiano escolar e social.

- Desenvolver as análises, incentivando processos de conversação e interação entre os alunos.

Tal fluxo de procedimentos requer do professor atenção ao tratamento conceitual dos conteúdos, de acordo com a seqüência de procedimentos sugerida. Acredita-se que com essa atenção pode haver um considerável ganho tanto na atenção do professor aos significados estruturantes dos conceitos, como nas previsões dos planos de ensino e na dinamização das aulas.

Chega-se, desse modo, ao final das análises deste ensaio, ou seja, do conjunto de idéias que constituem a sua argumentação, reafirmando-se o seu caráter introdutório e sugestivo, assim como a 
sua característica não dogmática, a sua inconclusão.

\section{CONSIDERAÇÃO FINAL}

$\mathrm{Na}$ argumentação construída neste ensaio, procurou-se, principalmente, formular uma proposição aos educadores no sentido de que considerem, inclusive para efeito de aprofundamento teórico e pesquisa, as possibilidades de aplicação de categorias da representação social ao ensino-aprendizagem.

Como se observou antes, o que se propõe neste ensaio não é novo, nos princípios didáticos, mas pode ser novo no modo de se (re) ver o sentido da representação social como forma de conhecimento prático que será aproveitado no processo de ensino-aprendizagem do conhecimento teórico.

Em síntese, reafirma-se a proposta de que o modo como as representações são "construídas e adquiridas" (MOSCOVICI, 2001, p. 62) também possa ser considerado no modo como se constroem e adquirem os conceitos teóricos.

\section{REFERÊNCIAS}

ABRIC, J. C. A abordagem estrutural das representações sociais. In: MOREIRA, A. S. P.; OLIVEIRA, D. C. de (Org.). Estudos interdisciplinares de representação social. Goiânia: $\mathrm{AB}, 1998$. p. 27-37.

ARNAY, José. Reflexões para um debate sobre a construção do conhecimento na escola: rumo a uma cultura científica escolar. In: RODRIGO, Maria José; ARNAY, José (Org.). Conhecimento cotidiano, escolar e científico: representação e mudança. São Paulo: Ática, 1998. p. 7-17.

ARRIGUCCI JUNIOR, D. O escorpião encalacrado. São Paulo: Perspectiva, 1973.

BAUER, Martin W.; GASKELL, George; ALLUM, N.C. Qualidade, quantidade e interesses do conhecimento. In: BAUER, M. W. Pesquisa qualitativa com texto, imagem e som. Petrópolis: Vozes, 2002. p. 17-36.

BRASIL. Ministério da Educação. Secretaria de Educação Fundamental. Referenciais para formação de professores. Brasília, 1999.

BURKE, P. The historical antropology of early modern Italy: essays on perception an communication. Cambridge: Cambridge University, 1987. 
CARDOSO, C. F.; MALERBA, J. (Org.). Representações: contribuição a um debate transdisciplinar. Campinas: Papirus, 2000.

FAZENDA, Ivani Catarina Arantes. Sobre a arte ou a estética do ato de pesquisar na educação. In . A pesquisa em educação e as transformações do conhecimento. Campinas (SP): Papirus, 1998, p. 11-16.

FERREIRA, A. B. de H. Dicionário brasileiro de língua portuguesa. Rio de Janeiro: Civilização Brasileira, 1986.

FLAMENT, C. Estrutura e dinâmica das representações sociais. In: JODELET, D. As representações sociais. Rio de Janeiro: EDUERJ, 2001. p. 155-172.

GOFFMAN, E. A representação do eu na vida cotidiana. Petrópolis: Vozes, 2002.

JODELET, Denise. Representações sociais: um domínio em expansão. In : 21. . As representações sociais. Rio de Janeiro: EDUERJ, 2001. p. 13-

JOVCHELOVITCH, S. Representações sociais e esfera pública. A construção simbólica dos espaços públicos no Brasil. Petrópolis: Vozes, 2000.

LEAHEY, T. H.; HARRIS, R. J. Aprendizaje y cognición. Madri: Prentice Hall, 2000.

LEFEBVRE, H. Lógica formal/lógica dialética. 3. ed. Rio de Janeiro: Civilização Brasileira, 1983.

MOREIRA, A. S. P.; OLIVEIRA, D. C. de (Org.). Estudos interdisciplinares de representação social. Goiânia: $\mathrm{AB}, 1998$.

MOSCOVICI, S. A representação social da psicanálise. Rio de Janeiro: Zahar, 1978.

. Das representações coletivas às representações sociais: elementos para uma história. In: JODELET, D. (Org.). As representações sociais. Rio de Janeiro: EDUERJ, 2001. p. 59-67

. Notes towards a description of social representations. European Journal of Social Psychology, n.18, p. 11-250, 1988.

OCHOA, R. F. Hacia una pedagogía del conocimiento. Santafé de Bogotá, Colômbia: McGraw-Hill, 2000.

PERRENOUD, P. et al (Org.). Formando professores profissionais: Quais estratégias? Quais competências? Porto Alegre: Artmed, 2001.

PINTO, M. da C. Um elogio ao ensaio. São Paulo: Ateliê Editorial, 1998. 
PIAGET, J. A equilibração das estruturas cognitivas. Rio de Janeiro: Zahar, 1976.

ROSA, D. E. Gonçalves; SOUZA, V. C. de. Didática e práticas de ensino: interfaces com diferentes saberes e lugares formativos. Rio de Janeiro: DF\&A, 2002.

SÁ, C. A construção do objeto de pesquisa em representações sociais. Rio de Janeiro: EDUERJ, 1998. 1996.

. Núcleo central das representações sociais. Petrópolis: Vozes,

SANTIAGO, R. A. A escola representada pelos alunos, pais e professores. Portugal: Universidade de Aveiro, 2000.

Encaminhado em: 30/08/07

Aceito em: 15/10/07 